\title{
The Importance of the Canonical Wnt Signaling Pathway in the Porcine Endometrial Stromal Stem/Progenitor Cells: Implications for Regeneration
}

\author{
Joanna Bukowska, ${ }^{1}$ Adam Janusz Ziecik, ${ }^{2}$ Joanna Laguna, ${ }^{1}$ Barbara Gawronska-Kozak, ${ }^{3}$ and Gabriel Bodek ${ }^{1}$
}

The regenerative ability of the endometrium is strongly associated with the presence of adult stem/progenitor cells. Purposes of the present study were (1) to establish the presence of stem/progenitor cells in porcine endometrial stroma using a clonogenic assay and (2) to investigate whether the canonical Wnt pathway affects the potential of stem/progenitor cells to undergo self-renewal or differentiation. The utility of endometrial stromal clones as a model for stem/progenitor studies was evaluated based on these cells' increased expression of mesenchymal stem cell (MSC) marker genes, including CD29, CD73, CD90, and CD105, compared with primary cultured cells. Small molecules were introduced to activate (BIO) or inhibit (XAV939) the canonical Wnt pathway during stromal clone formation. Cloning efficiency assays revealed that activation of the $\mathrm{Wnt} / \beta$-catenin pathway promoted formation of more differentiated small clones. Moreover, activation of the Wnt/ $\beta$-catenin pathway decreased, whereas inhibition of the pathway increased MSC marker expression. Additionally, we confirmed the importance of canonical Wnt pathway stimulation in endometrial stromal cells through observing the appropriate changes in $\beta$-catenin cellular localization. These data indicate that modulation of the canonical Wnt pathway effects the process of regeneration in the porcine endometrium during the course of the estrous cycle.

\section{Introduction}

A DULT STEM CELLS can replace cells within tissues that have either a high turnover rate, such as blood, vascular endothelium, skin epithelium, intestinal epithelium, and respiratory tract, or those that have a high regenerative potential upon injury or disease, such as skeletal muscle, liver, pancreas, and bone [1].

The endometrium is the mucosal lining of the uterus, and a highly regenerative tissue that undergoes cycles of growth, proliferation, differentiation, and regression. Endometrial renewal is crucial for preparation of the uterus for embryo implantation and pregnancy maintenance in humans and animals. It has been hypothesized that the regenerative ability of the endometrium is strongly associated with the presence of adult stem/progenitor cells. To date, several studies have provided evidence for the existence of putative epithelial and stromal stem cells in human [2-4], mouse [5,6], cow [7], and porcine endometrium [8,9]. In pigs, the endometrial stroma contains a small population of stem cells referred to as side population (SP) cells, which were identified based on their ability to efflux toxic substances [8].
Moreover, SP cells have several stem-like properties: (1) clonogenicity; (2) multipotency due to their ability to differentiate into adipocytes, chondrocytes, and osteocytes in vitro; and (3) expression of mesenchymal stem cell (MSC) marker genes, including CD29, CD73, CD90, and CD105, and pluripotency markers, such as NANOG, SOX2, and POU5F1 $[8,9]$.

MSCs are postulated to be required for remodeling of the endometrial stromal compartment, and they are mainly defined by their functional properties, such as their extensive capacity for self-renewal and ability to undergo multilineage differentiation. Adult stem cells, such as MSCs, have been identified and characterized based on their unique expression of marker genes and combinations of specific proteins. Among the numerous approaches designed to study MSC properties, in vitro clonogenic assays, which measure the ability of single cells to produce clones when seeded at low densities, are used extensively $[2,8,10]$.

Multiple signaling pathways have been shown to participate in tissue regeneration and development. In the endometrium, cyclical regeneration is regulated by the steroid hormones estradiol $\left(\mathrm{E}_{2}\right)$ and progesterone $\left(\mathrm{P}_{4}\right)$. In the proliferative phase

\footnotetext{
${ }^{1}$ In Vitro and Cell Biotechnology Laboratory, ${ }^{2}$ Department of Hormonal Action Mechanisms, and ${ }^{3}$ Department of Biological Function of Food, Institute of Animal Reproduction and Food Research, Polish Academy of Sciences, Olsztyn, Poland.

(C) Joanna Bukowska, et al., 2015; Published by Mary Ann Liebert, Inc. This Open Access article is distributed under the terms of the Creative Commons Attribution Noncommercial License (http://creativecommons.org/licenses/by-nc/4.0/) which permits any noncommercial use, distribution, and reproduction in any medium, provided the original author(s) and the source are credited.
} 
of the estrous cycle, $E_{2}$ promotes expansion of the endometrial layer by activating cell proliferation, whereas during the secretory phase, $\mathrm{P}_{4}$ induces differentiation of endometrial cells [11]. It has been postulated that steroid hormones act through the canonical Wnt signaling pathway, which is referred to as the $\mathrm{Wnt} / \beta$-catenin pathway, in human endometrium. Increased $E_{2}$ levels activate the $\mathrm{Wnt} / \beta$-catenin pathway, whereas elevated $\mathrm{P}_{4}$ levels inhibit the Wnt/ $\beta$ catenin pathway, thereby counterbalancing the $\mathrm{E}_{2}$-enhanced proliferation [12].

The Wnt pathway is critical for uterine development and plays an important role during implantation and decidualization in mice [13], but its function in regeneration of the endometrium is still unclear. The canonical Wnt signaling pathway plays a vital role in the maintenance of selfrenewal and regulation of differentiation in various stem cell types. Many studies have shown that Wnt/ $\beta$-catenin signaling is required for stemness and pluripotency of embryonic stem (ES) cells, and it also has a supportive role in maintaining ES cell characteristics in vitro [14]. In hematopoietic stem cells (HSCs), various Wnt ligands support self-renewal and proliferation [15]. Furthermore, Wnt signaling is important for regulating proper stem cell maintenance and differentiation in the intestine [16,17].

Recent evidence indicates that the canonical Wnt pathway is also functional in MSCs. Human MSCs express a number of Wnt ligands, receptors, coreceptors, and inhibitors [18]. Exogenous application of the Wnt ligand Wnt3a to cell culture has a proliferative effect on the MSC population and results in enhanced self-renewal and inhibition of apoptosis [19].

Intense research efforts have focused on the application of small molecules that modulate the $\mathrm{Wnt} / \beta$-catenin signaling pathway to determine its function in different cell types. Using this strategy, the Wnt pathway has been shown to be inappropriately activated in many types of cancer [20,21]. In SW480 cells, treatment with the Wnt/ $\beta$-catenin inhibitor XAV939 blocks Wnt signaling and promotes $\beta$-catenin destruction [21]. Therefore, it has been proposed that inhibition of Wnt signaling could be an attractive strategy for cancer therapeutics. Conversely, activation of Wnt signaling using inhibitors of glycogen synthase kinase 3 (GSK-3), such as $\mathrm{BIO}$ or lithium chloride, prevents degradation of $\beta$-catenin [22]. Administration of GSK-3 inhibitors improves the selfrenewal ability of HSCs in nonobese, diabetic severe combined immunodeficiency mice, suggesting that GSK-3 inhibitors enhance stem cell self-renewal [23]. Conversely, in human ES cells (hESCs), activation of $\mathrm{Wnt} / \beta$-catenin signaling by application of exogenous Wnt3a or BIO promotes loss of self-renewal and drives transcriptional changes typical of differentiation into mesoderm lineages [24].

A pattern of Wnt-related gene expression is similar to that of the basalis epithelium of menstrual endometrium [25], suggesting that the canonical Wnt signaling pathway has an important role in the regulation of a putative endometrial stem cell population. However, relatively little is known about the role of the canonical Wnt signaling pathway in endometrial stem cells in the pig. Kiewisz et al. showed that Wnt pathway members, including Wnt 4 , Wnt5A, $\beta$-catenin, and E-cadherin, are expressed in the luminal and glandular epithelium of porcine endometrium during the peri-implantation period of pregnancy and at the luteal phase of the estrous cycle [26]. Furthermore, WNT5A and WNT7A have different expression patterns during the estrous cycle compared to pregnancy, suggesting that these Wnt family members are hormonally regulated. There are no data concerning the role of the canonical Wnt pathway in regulating self-renewal and differentiation of endometrial stem cells. Thus, in the present study we used a small molecule inhibitor (XAV939) and activator (BIO) of the $\mathrm{Wnt} / \beta$-catenin pathway to investigate the role of Wnt signaling in self-renewal and differentiation of stem/ progenitor cells in the porcine endometrium.

\section{Materials and Methods}

Uteri $(n=9)$ were collected postmortem from cyclic, crossbred pigs (Sus scrofa domesticus) at a local abattoir. Immediately after slaughter, uteri were collected and transported on ice to the laboratory. To examine the effect of endocrine status on stromal cells, endometrial samples were obtained at days 2-4 (early diestrus, $n=5-7$ ) of the estrous cycle, when corpora lutea begin to produce progesterone and its concentration is present in the blood plasma. During this phase, endometrial stromal cells gradually differentiate to achieve uterine receptivity for embryo implantation. The second group of cells was collected at days 19-20 (proestrus, $n=4$ ) of the estrous cycle, when $17 \beta$-estradiol is high [27] and during which extensive cellular proliferation occurs.

The phases of the estrous cycle were verified based on macroscopic observation of the ovaries. Early diestrus is characterized by the presence of corpora hemorrhagica, whereas proestrus, which occurs just before ovulation, is characterized by the presence of numerous ovulatory follicles (7-10 $\mathrm{mm}$ in diameter) that were rich in ovarian fluid [28]. All studies were approved by the Animal Ethics Committee at the University of Warmia and Mazury in Olsztyn, Poland (Agreement No. 39/2012).

\section{Isolation and culture of primary endometrial stromal cells}

Uterine horns were cut longitudinally and endometrial tissues were subjected to enzymatic digestion, according to a procedure described previously by Bodek et al. [8]. Briefly, to separate stromal tissue from epithelial cells, endometrial tissues were digested with $1 \mathrm{IU} / \mathrm{mL}$ dispase (Sigma-Aldrich) for $75 \mathrm{~min}$ at $37^{\circ} \mathrm{C}$ in Hanks' balanced salt solution (HBSS) at $\mathrm{pH} 7.4$ (Sigma-Aldrich), and then filtered through nylon mesh. The epithelial cells were discarded, and the remaining endometrial tissue was digested for $80 \mathrm{~min}$ in $0.06 \%$ collagenase I (Biochrom) in HBSS supplemented with $1 \%$ bovine serum albumin (BSA; Sigma-Aldrich). The endometrial stromal cell suspension was filtered and collected by a series of three centrifugations $(218 \mathrm{~g}, 10 \mathrm{~min})$.

The pelleted cells were suspended in Dulbecco's modified Eagle's medium (DMEM/F-12; Life Technologies) containing $10 \%$ fetal bovine serum (FBS), $100 \mathrm{IU} / \mathrm{mL}$ penicillin, $100 \mu \mathrm{g} / \mathrm{mL}$ streptomycin, and amphotericin $\mathrm{B}$, and seeded on 100-mm, tissue culture-treated Petri dishes at $37^{\circ} \mathrm{C}$ in a $5 \% \mathrm{CO}_{2}$ and $95 \%$ air atmosphere $(P=0)$. The same volume of endometrial tissue was always processed, although cells were not counted before initial seeding. After $18 \mathrm{~h}$ the nonadherent and dead cells were removed and fresh medium was added. The primary cultured endometrial stromal cells $(P=0)$ were used for further experiments. 


\section{Isolation and culture of bone marrow stromal cells}

Bone marrow aspirates were taken from the femoral bone and iliac crest $(n=4)$. The aspirates were suspended in DMEM/ F-12 medium (Life Technologies) containing 10\% FBS, 100 $\mathrm{IU} / \mathrm{mL}$ penicillin, $100 \mu \mathrm{g} / \mathrm{mL}$ streptomycin, amphotericin B, and $2 \mathrm{mM}$ ethylenediaminetetraacetate (EDTA) (SigmaAldrich). The aspirate suspension was filtered and collected by centrifugation $(218 g, 10 \mathrm{~min})$, and the pelleted cells were resuspended in complete culture medium and plated on $60-\mathrm{mm}$, tissue culture-treated Petri dishes. After $24 \mathrm{~h}$, the nonadherent cells were removed. The adherent cells were cultured for 14-21 days. The primary cultured bone marrow stromal cells $(P=0)$ and cells at passage $1(P=1)$ were used for the experiments.

\section{Clonogenicity assay}

To obtain endometrial stromal clones, cells $(P=1)$ were detached with $0.025 \%$ trypsin with EDTA (Life Technologies) and seeded at a clonal density of 300 cells $/ \mathrm{cm}^{2}$ on $60-\mathrm{mm}$, tissue culture-treated Petri dishes. Clonal density of 300 cells/ $\mathrm{cm}^{2}$ provides optimal conditions for development of stromal clones preventing their overlap during long-term in vitro culture. The cells were cultured for 14 days in phenol red-free DMEM/F12 medium supplemented with 10\% FBS, 100 IU/ $\mathrm{mL}$ penicillin, $100 \mu \mathrm{g} / \mathrm{mL}$ streptomycin, and amphotericin B. The cultures were monitored three times per week to ensure that the clones grew from single cells. The clones at passage 2 $(P=2)$, which were distinguished as large or small, and the primary cultured stromal cells $(P=0)$ were collected in Fenozol (A\&A Biotechnology) at the end of each culture period and stored frozen until RNA isolation.

\section{Flow cytometry analysis of MSC markers}

The endometrial stromal cells were phenotypically analyzed by flow cytometry, according to a modified procedure described previously by Gawronska-Kozak et al. [29]. In brief, stromal cells at days 2-4 $(n=3)$ and days 19-20 $(n=3)$ of the estrous cycle were cryopreserved in $50 \%$ FBS, $10 \%$ dimethyl sulfoxide (DMSO), and 40\% DMEM/F-12 medium. One day before flow cytometry analysis, individual vials of cells were thawed, centrifuged, and plated in 100-mm, tissue culturetreated Petri dishes. On the day of analysis, the nonadherent cells were washed out with PBS, and the adherent cells were detached with Accutase (Life Technologies).

Then, the cells were suspended in $0.1 \%$ BSA in HBSS at a concentration of $1 \times 10^{6}$ per tube and incubated for $45 \mathrm{~min}$ with the following antibodies (BD Pharmingen): CD29 (1:5, clone MAR4), CD73 (1:20, clone AD2), CD90 (1:20, clone 5E19), CD105 (1:20, clone 266), hematopoietic cells marker CD45 (1:10; AbD Serotec). Isotype-matched immunoglobulins, used in the same concentrations as that of the primary antibody, served as controls for nonspecific immunofluorescence. The labeled cells were analyzed using a BD FACSAriaII Cell Sorter (Becton Dickinson) and BD FACSDiva v6.1.3 Software (Becton Dickinson). Histograms were overlapped using Flowing Software Version 2.5.0 (Cell Imaging Core, Turku BioImaging; Turku Centre for Biotechnology, University of Turku, Abo Akademi University). The total number of cells analyzed for each sample was 10,000 . The positive cells were identified by comparison with mouse IgG1 as isotype control.

\section{Long-term effects of XAV939 and BIO on clonogenicity and MSC marker gene expression in endometrial stromal cells}

During the entire 2 week culture period, developing clones $(P=1)$ initiated by the single cells seeded at clonal density of 300 cells $/ \mathrm{cm}^{2}$, were separately treated with different doses of the small molecules BIO (6-bromoindirubin-3'-oxime; SigmaAldrich), a Wnt/ $\beta$-catenin pathway activator, and XAV939 $(3,5,7,8$-Tetrahydro-2-[4-(trifluoromethyl)phenyl]-4Hthiopyrano[4,3-d]pyrimidin-4-one; Sigma-Aldrich), a selective inhibitor of $\beta$-catenin transcription. The stimulator doses used were 1 or $2 \mu \mathrm{M}$ for BIO and 2.5, 5, or $10 \mu \mathrm{M}$ for XAV939. These treatment doses were chosen based on previously described in vitro data using XAV939 in human cancer cells [30] and BIO in hESCs [24] to modulate Wnt/ $\beta$-catenin signaling. For controls, unstimulated cultures were incubated in medium supplemented with $0.05 \%$ DMSO.

Media supplemented with freshly added stimulators were changed twice a week. At the end of the culture period, stromal clones that contained between 50 and 100 cells were classified as small, and those that consisted of more than 100 cells were classified as large [8]. Both types of clones were separately counted. The cloning efficiency (CE) was calculated using the following formula: CE $(\%)=$ (number of colonies/number of cells seeded) $\times 100 \%$. After counting, the clones were washed with PBS and collected in Fenozol for RNA extraction.

\section{Detection of $\beta$-catenin localization by immunofluorescence}

The localization of $\beta$-catenin in endometrial stromal cells was detected by immunofluorescence staining. Cells $\left(6 \times 10^{4}\right)$ isolated from pigs at days 2-4 of the estrous cycle were seeded on $13 \mathrm{~mm}$ glass slides (Nalgene Nunc International) and incubated for $18 \mathrm{~h}$ with BIO $(2 \mu \mathrm{M})$, XAV939 $(10 \mu \mathrm{M})$, or control medium. The treatment doses were chosen based on results from the clonogenic assay and expression of MSC markers (compare Figs. 3 and 5). After $24 \mathrm{~h}$, the cells were washed with warm PBS, fixed with $4 \%$ paraformaldehyde, permeabilized for 20 min with Tris-buffered saline (TBS) at $\mathrm{pH} 7.4$ containing $0.2 \%$ Triton X-100 (TBS-T), and blocked for $1 \mathrm{~h}$ in $2.5 \%$ normal donkey serum (Jackson ImmunoResearch) in polymyxinanisomycin-vancomycin solution (0.1 M PBS, 0.1\% BSA, $0.05 \%$ thiomersal).

Subsequently, the cells were incubated with an anti- $\beta$-catenin antibody (1:100; BD Transduction Laboratories) and negative control mouse IgG1 antibody (1:100; Dako Cytomation) overnight at $4^{\circ} \mathrm{C}$. The next day, the cells were washed with TBS, incubated with CY3-conjugated donkey anti-mouse IgG (1:2,000; Jackson ImmunoResearch) for $1 \mathrm{~h}$ at room temperature, and then mounted using VECTASHIELD mounting medium (Vector Laboratories). Images were acquired using a Nikon Eclipse Ti-E confocal microscope.

\section{Effect of small molecules on multilineage differentiation potential of endometrial stromal cells}

Endometrial stromal cells were seeded at the concentration of $2.5 \times 10^{5}$ into 24 -well plates $(P=1)$. After reaching subconfluency, adipogenic, osteogenic, and chondrogenic 
differentiation was induced, according to the procedure described previously by Bodek et al. [8] and GawronskaKozak [31]. Adipogenic medium I consisted of DMEM/F12 supplemented with $5 \% \mathrm{FBS}, 1.7 \mu \mathrm{M}$ insulin (SigmaAldrich), $1 \mu \mathrm{M}$ dexamethasone (Sigma-Aldrich), $0.5 \mathrm{mM}$ isobutyl-methylxanthine (IBMX; Sigma-Aldrich). Adipogenic medium II consisted of DMEM/F12 supplemented with 5\% FBS, $17 \mathrm{nM}$ insulin, $2 \mu \mathrm{M}$ troglitazone (SigmaAldrich). Stromal cells were exposed for $48 \mathrm{~h}$ to adipogenic medium I. For the next 18 days, cells were exposed to adipogenic medium II. For chondrogenic and osteogenic induction StemPro1 Chondrogenesis Differentiation Kit (Life Technologies) and Stem-Pro1 Osteogenesis Differentiation Kit (Life Technologies) were used, respectively.

To investigate the effect of the canonical Wnt pathway activation on cell differentiation potency, culture media were supplemented with 1 and $2 \mu \mathrm{M}$ of BIO. To adapt the cells to differentiation conditions, cultures were incubated for $6 \mathrm{~h}$ without BIO supplementation and then BIO was added. For controls, cultures were incubated only in medium DMEM/F12 supplemented with 1 and $2 \mu \mathrm{M}$ of BIO and in medium DMEM/F12 with no treatments. The culture media with freshly added stimulators were replaced every 3 or 4 days. Cells were cultured for 20, 12, 7 days in adipogenic-, osteogenic-, and chondrogenic-induced media, respectively. Differentiated phenotype was observed by light microscopy and confirmed by the expression of marker genes by realtime polymerase chain reaction (PCR).

The ability to spontaneous multilineage differentiation was verified in the endometrial stromal clones. In clones cultured for 14 days in DMEM/F12 supplemented with $10 \%$ FBS, 100 $\mathrm{IU} / \mathrm{mL}$ penicillin, $100 \mu \mathrm{g} / \mathrm{mL}$ streptomycin, amphotericin B, and treated with BIO (1 and $2 \mu \mathrm{M})$ and XAV $939(2.5,5$ and $10 \mu \mathrm{M})$ the presence of specific marker genes was performed by real-time PCR. Adipogenic, osteogenic, and chondrogenic differentiation was detected with Oil Red Oil, Alizarin Red Solution, and Alcian blue staining, respectively.

\section{RNA isolation}

Total RNA was isolated using the Total RNA Mini Kit (A\&A Biotechnology), according to the manufacturer's protocol. The RNA concentration and quality were determined spectrophotometrically using an ND-1000 spectrophotometer (NanoDrop Technologies). Isolated total RNA samples were stored at $-80^{\circ} \mathrm{C}$.

\section{Reverse transcription}

Genomic DNA was removed from RNA samples using DNase I, Amplification Grade (Invitrogen). cDNA was synthesized from $1 \mu \mathrm{g}$ total RNA using the High-Capacity cDNA Reverse Transcription Kit (Applied Biosystems), according to the manufacturer's protocol. The cDNA was stored at $-20^{\circ} \mathrm{C}$ before real-time PCR analysis.

\section{Real-time PCR}

Real-time PCR was performed on the ABI ViiA 7 sequence detection system (Life Technologies Holding Pte Ltd) using the following conditions: $95^{\circ} \mathrm{C}$ for $3 \mathrm{~min}$ (initial denaturation), followed by 40 repetitive cycles of $95^{\circ} \mathrm{C}$ for $10 \mathrm{~s}$ (denaturation) and $59^{\circ} \mathrm{C}$ for $20 \mathrm{~s}$ (annealing). Primers for $P P I B, C D 29, C D 73, C D 90, C D 105, L P L, A C A N$, and $B G L A P$ were designed based on sequences obtained from the National Center for Biotechnology Information and were described previously $[8,32]$. The final volume of the reaction mixture was $10 \mu \mathrm{L}$, and consisted of $1 \mu \mathrm{L}$ cDNA (50 ng), $0.4 \mu \mathrm{L}(200 \mathrm{nM})$ each of the forward and reverse primers, $3 \mu \mathrm{L}$ nuclease-free water, $5 \mu \mathrm{L}$ KAPA SYBR ${ }^{\circledR}$ Fast quantitative polymerase chain reaction master mix, and $0.2 \mu \mathrm{L}$ ROX Low reference dye (KAPA Biosystems). As a negative control, samples were prepared using nuclease-free water instead of cDNA. Proper amplification of genes was verified by melting curve analysis. The real-time data were normalized on the basis of $P P I B$ content and analyzed using the Zhao and Fernald method [33].

\section{Statistical analyses}

Statistical analyses were performed using the GraphPad PRISM v6.02 software (GraphPad Software). Two-way analysis of variance (ANOVA) followed by Bonferroni's post hoc test was used to compare the expression of MSC markers (CD29, CD73, CD90, CD105) in primary cultured stromal cells and clones at days 2-4 and 19-20 of the estrous cycle. One-way ANOVA analysis followed by the Bonferroni's post hoc test was performed to test for significant differences in CEs and the expression levels of CD29, CD73, CD90, CD105, following treatment with different doses of BIO and XAV939. Data are expressed as mean + standard error of the mean. A value of $P<0.05$ was considered statistically significant.

\section{Results}

\section{Phenotype of endometrial stromal cells}

The expression of MSC markers, including CD29, CD73, CD90, and CD105, on porcine endometrial stromal cells isolated from pigs in diestrus and proestrus was analyzed using flow cytometry. All of the endometrial stromal cells showed high levels of CD29 (Fig. 1A) and CD90 (Fig. 1B), but were negative for CD73 (Fig. 1C) and CD105 (Fig. 1D), regardless of the stage of the estrous cycle. Overall, $97.5 \% \pm 0.9 \%$ and $96.5 \% \pm 1.49 \%$ of endometrial stromal cells isolated from uteri in diestrus and proestrus, respectively, were positive for CD90. Stromal cells positive for CD29 represented $83.6 \% \pm 4.9 \%$ in diestrus and $83.9 \% \pm 6.9 \%$ in proestrus (Table 1). Endometrial cells $(>98 \%)$ were negative for the specific hematopoietic marker CD45 (Fig. 1E and Table 1). These data indicate that the studied population of endometrial stromal cells is of mesenchymal origin.

\section{Establishment of cell clones from endometrial stroma}

The endometrial stromal cells seeded at clonal density (300 cells $/ \mathrm{cm}^{2}$ ) generated single cell-derived clones (Fig. 2). The individual cells started to proliferate 2-3 days after plating, creating small clusters of cells (Fig. 2A). The stromal clones developed gradually (Fig. 2B), but continued to expand over the next several days of culture. Two types of stromal clones were distinguished at the end of the 2 week culture period: large, densely packed clones with a high proliferation capacity (Fig. 2C) and small, loosely arranged clones with a low number of cells (Fig. 2D). 

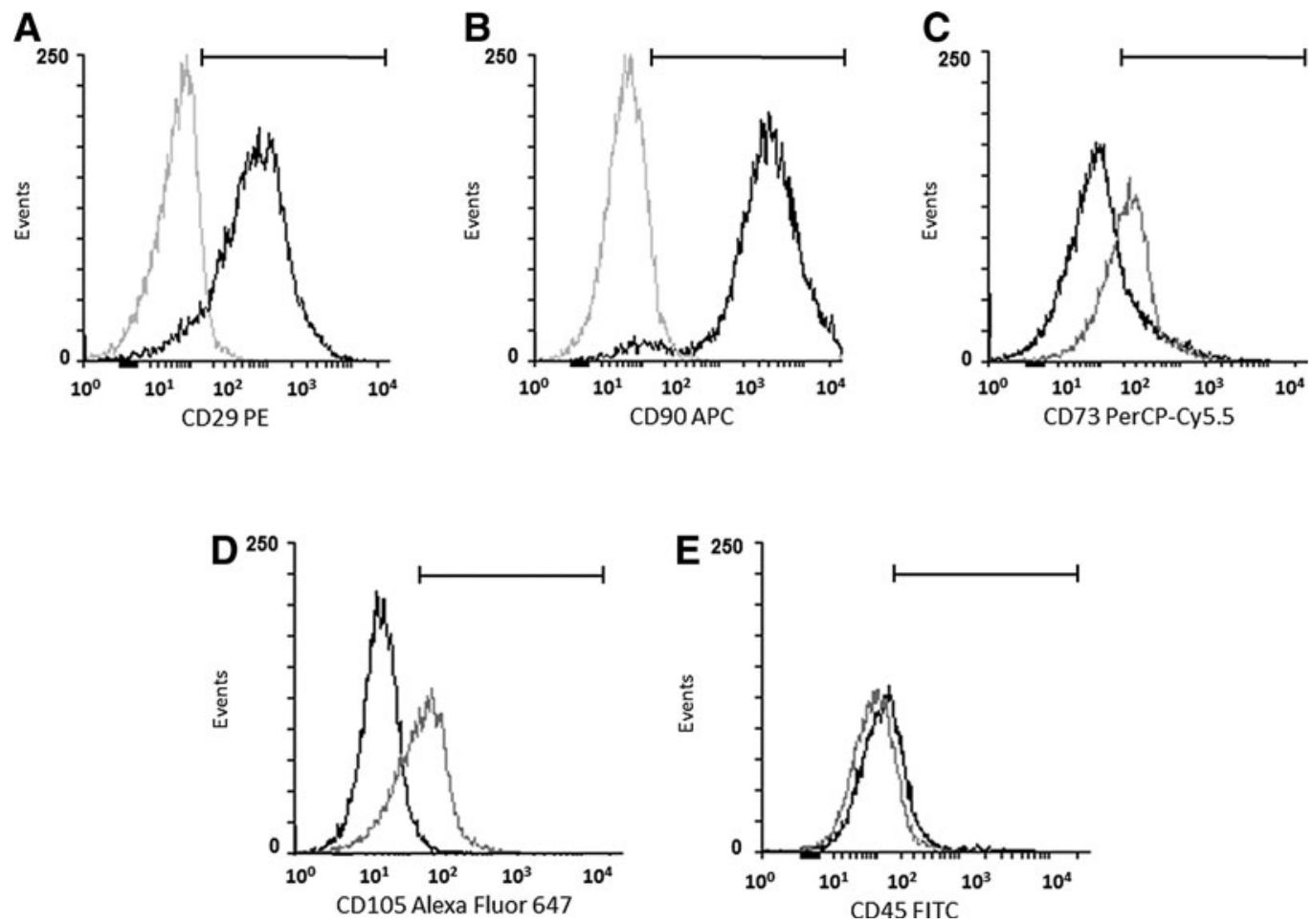

FIG. 1. Immunophenotype of endometrial stromal cells for MSC markers (A) CD29, (B) CD90, (C) CD73, (D) CD105, and (E) hematopoietic stem cell marker CD45. The histograms are representative for all three samples $(n=3$; biological repeats) collected on days 2-4 $(n=3)$ and on days 19-20 $(n=3)$ of the estrous cycle (black lines). Gray lines indicate background fluorescence obtained with isotype control IgG. MSC, mesenchymal stem cell.

\section{Expression of MSC marker mRNA in endometrial stromal clones and primary cell culture}

To determine whether porcine endometrial stromal clones exhibit MSC characteristics, we analyzed the expression of MSC markers, including CD29, CD73, CD90, and CD105, by real-time PCR. The MSC marker expression levels in the endometrial stromal clones were compared to those measured in primary cultured endometrial stromal cells and bone marrow-derived cells. The stromal clones derived from pigs at days $2-4$ of the estrous cycle showed higher expression levels of $C D 29$ and $C D 90$ than primary cultured stromal cells $(P<0.001 ;$ Fig. 3A, C, bright bars). Similarly,

Table 1. ImMunophenotypic ChaRACTERISTICS OF THE Endometrial Stromal Cells Isolated on Days 2-4 $(N=3)$ and on Days 19-20 $(N=3)$ of the Estrous CyCle

\begin{tabular}{lccc}
\hline & & \multicolumn{2}{c}{ Positive cells $(\%)$} \\
\cline { 3 - 4 } & & \multicolumn{2}{c}{ Days of estrous cycle } \\
\cline { 3 - 4 } Markers & FACS analysis & $2-4$ & $19-20$ \\
\hline CD29 & Positive & $83.6 \pm 4.9$ & $83.9 \pm 6.9$ \\
CD90 & Positive & $97.5 \pm 0.9$ & $96.5 \pm 1.49$ \\
CD73 & Negative & 0.0 & 0.0 \\
CD105 & Negative & 0.0 & 0.0 \\
CD45 & Negative & $0.8 \pm 0.25$ & $1.8 \pm 0.5$ \\
\hline
\end{tabular}

All values reflect the mean of percent \pm standard error of the mean of three replicates (individuals) in each group.

FACS, fluorescence-activated cell sorting. the stromal clones derived from pigs at days $19-20$ of the estrous cycle showed significantly elevated levels of $C D 29$, $C D 73$, and $C D 90$ compared with the primary cultured stromal cells $(P<0.01$ for $C D 29$ and for $C D 90, P<0.05$ for $C D 73$; Fig. 3A, C, B, dark bars). There were no differences between CD105 levels expressed in stromal clones and primary cultured stromal cells (Fig. 3D). Generally, the endometrial clones showed higher levels of MSC marker gene expression than primary cells, regardless of the stage of the estrous cycle. The levels of MSC gene expression in stromal clones were similar to those observed in bone marrow cells. These results indicate that the endometrial stromal clones represent the MSC population in porcine endometrial stroma.

\section{Long-term effect of XAV939 and BIO on the clonogenicity of endometrial stromal cells}

To determine whether the canonical Wnt pathway regulates the clonogenicity of adult endometrial stromal stem/progenitor cells, the clonogenic assay was employed. Endometrial stromal clones were cultured in media supplemented with different doses of the Wnt pathway inhibitor XAV939 or the Wnt pathway activator BIO, and the number of developing clones was calculated (Fig. 4). CE analysis revealed that BIO strongly affected large and small clone development of endometrial stromal cells isolated at days 2-4 of the estrous cycle (Fig. 4A, B). At a concentration of $1 \mu \mathrm{M}$, BIO treatment reduced the number of large clones $(P<0.05$; Fig. $4 \mathrm{~A})$, and at $2 \mu \mathrm{M}$, BIO treatment completely blocked large clone formation (Fig. 4A). The opposite effect was detected for small clones, which showed the 
FIG. 2. Representative photos of endometrial stromal clones at different stages of in vitro development. (A) An image shows a single-cell division at days 2-3 of culture. (B) A subset of cells after 7 days of culture is shown. (C) A large, densely arranged clone at day 14 of culture is shown. (D) A small clone with loosely packed cells at day 14 of culture is shown. Scale bars: $100 \mu \mathrm{m}$ (A, B), $500 \mu \mathrm{m}$ (C, D).

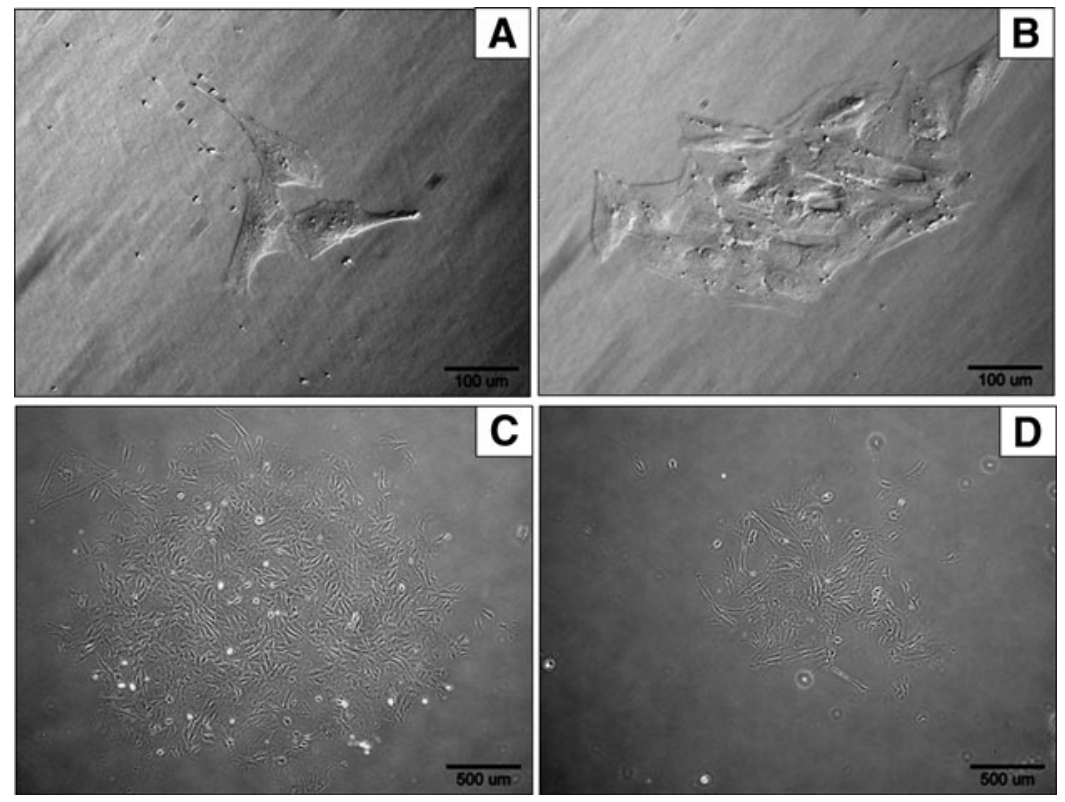

significantly elevated number with $\mathrm{BIO}$ administration $(1 \mu \mathrm{M})$ compared with the control group $(P<0.001$; Fig. 4B).

Similar effects were observed for clones established from endometrial stromal cells isolated at days 19-20 of the estrous cycle (Fig. 4C, D). The presence of BIO at 1 or $2 \mu \mathrm{M}$ in the culture medium reduced the number of large clones $(P<0.01 ; P<0.0001$, respectively; Fig. 4C). On the contrary, the $\mathrm{CE}$ of small clones significantly increased with 1 and $2 \mu \mathrm{M}$ BIO administration compared with the control group $(P<0.01 ; P<0.001$, respectively; Fig. 4D). In contrast to BIO, XAV939 did not affect the number or type of clones in culture, regardless of the stage of the estrous cycle (Fig. 4A-D).

To establish the mechanism of Wnt pathway modulation in porcine endometrial stromal cells, we examined changes in $\beta$-catenin localization following stimulator treatment
(Fig. 5). Activation of the $\mathrm{Wnt} / \beta$-catenin pathway by $\mathrm{BIO}$ $(2 \mu \mathrm{M})$ resulted in an accumulation of $\beta$-catenin in the nucleus (Fig. 5A). In contrast, XAV939 $(10 \mu \mathrm{M})$ did not show significant effect on staining of cytoplasmic $\beta$-catenin (Fig. $5 B)$. These data indicate that the endometrial stromal cells respond appropriately to Wnt pathway activation.

\section{Long-term effect of XAV939 and BIO on MSC marker expression in endometrial stromal clones}

To verify whether the $\mathrm{Wnt} / \beta$-catenin pathway affects endometrial stromal stem/progenitor cells development, we evaluated the effect of XAV939 and BIO on MSC marker expression (Fig. 6). In clones $(P=1)$ derived from stromal cells isolated at days $2-4$ of the estrous cycle, BIO treatment downregulated the expression of $C D 73(P<0.05$ for $1 \mu \mathrm{M}$
FIG. 3. Expression of MSC markers (A) CD29, (B) CD73, (C) CD90, and (D) CD105 in primary cultured stromal cells and stromal clones collected from pigs at days 2-4 (bright bars; $n=4-7)$ and days $19-20$ of the estrous cycle (dark bars; $n=4-5$ ) compared with the bone marrow MSC (white bars; $n=4$ ). Bars with various letters are different among groups of endometrial cells isolated on days 2-4 and 19-20 of the estrous cycle (small letters for endometrial stromal cells isolated on days 2-4 of the estrous cycle; capital letters for cells collected on days 19-20 of the estrous cycle). The results are shown as the mean + SEM of four to seven biological replicates. BM, bone marrow; SEM, standard error of the mean.
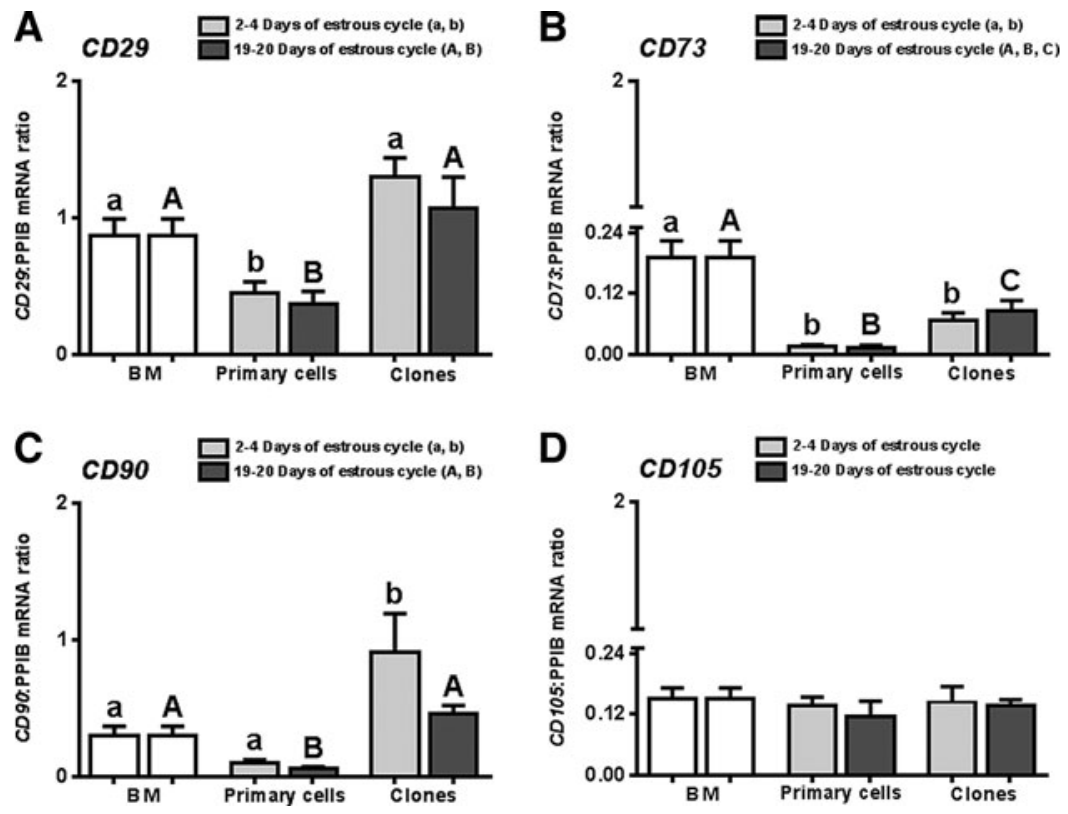

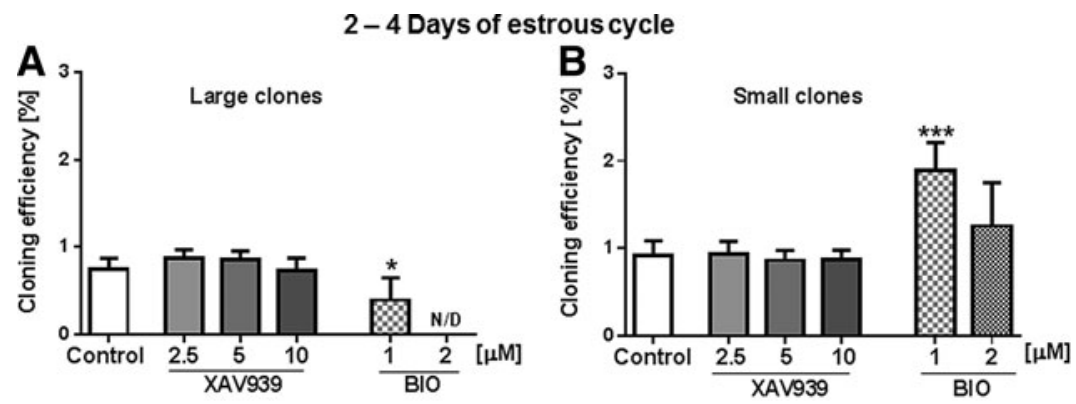

FIG. 4. Effect of XAV939 and BIO on the clonogenicity of endometrial stromal cells in vitro. The CEs (\%) were calculated for days 2-4 (A, B) and days 19-20 (C, D) of the estrous cycle. The results are shown as the mean + SEM of four to five biological replicates. Six repeats of each sample were performed per treatment. The asterisks indicate
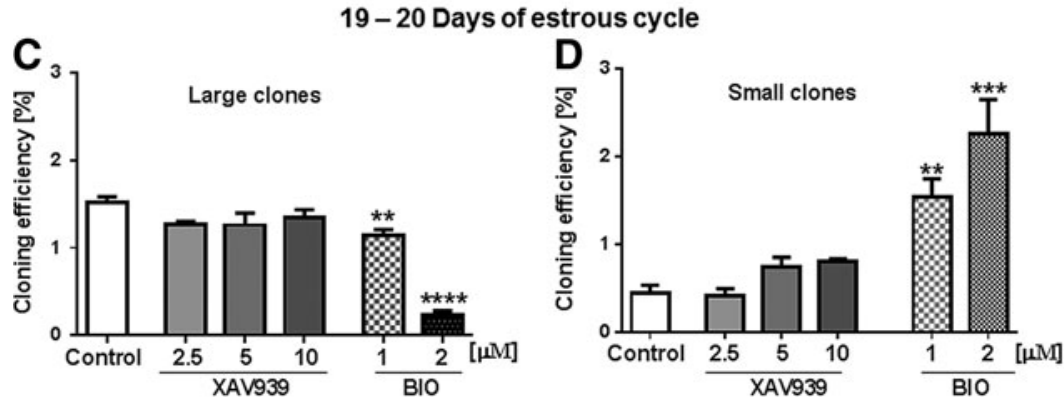
significant differences in cloning efficiencies between groups treated with different stimulator doses relative to the control $(* P<0.05$; $* * P<0.01 ; \quad * * * P<0.001 ; \quad * * * * P<0.0001)$. $\mathrm{CE}$, cloning efficiency; N/D, nondetectable.

BIO; $P<0.01$ for $2 \mu \mathrm{M}$ BIO), $C D 90(P<0.05$ for $2 \mu \mathrm{M}$ $\mathrm{BIO})$, and $C D 105(P<0.05$ for $2 \mu \mathrm{M} \mathrm{BIO})$ (Fig. 6A). In contrast, XAV939 treatment increased the level of $C D 73$ in a dose-dependent manner $(P<0.05$ for $2.5 \mu \mathrm{M}$ XAV939; $P<0.01$ for 5 and $10 \mu \mathrm{M}$ XAV939), whereas no effects were observed on CD29, CD90, or CD105 levels (Fig. 6B).

In clones derived from stromal cells isolated at days 1920 of the estrous cycle, $2 \mu \mathrm{M}$ BIO treatment decreased the levels of $C D 73(P<0.05), C D 90(P<0.05)$, and $C D 105$ $(P<0.01)$ compared with control, unstimulated cultures
(Fig. 6C). In contrast, XAV939 treatment increased the expression of $C D 73(P<0.01$ for $2.5 \mu \mathrm{M}$ XAV939; $P<0.01$ for $5 \mu \mathrm{M}$ XAV939; $P<0.001$ for $10 \mu \mathrm{M}$ XAV939) and $C D 105(P<0.05 ; P<0.01 ; P<0.001$ for $2.5,5$, and $10 \mu \mathrm{M}$ XAV939, respectively) (Fig. 6D). There was also an increase in CD90 levels with XAV939 treatment compared with the control group, but the differences did not reach statistical significance (Fig. 6D). Therefore, activation of the canonical Wnt pathway decreased, whereas inhibition of the Wnt pathway increased the expression of MSC markers in
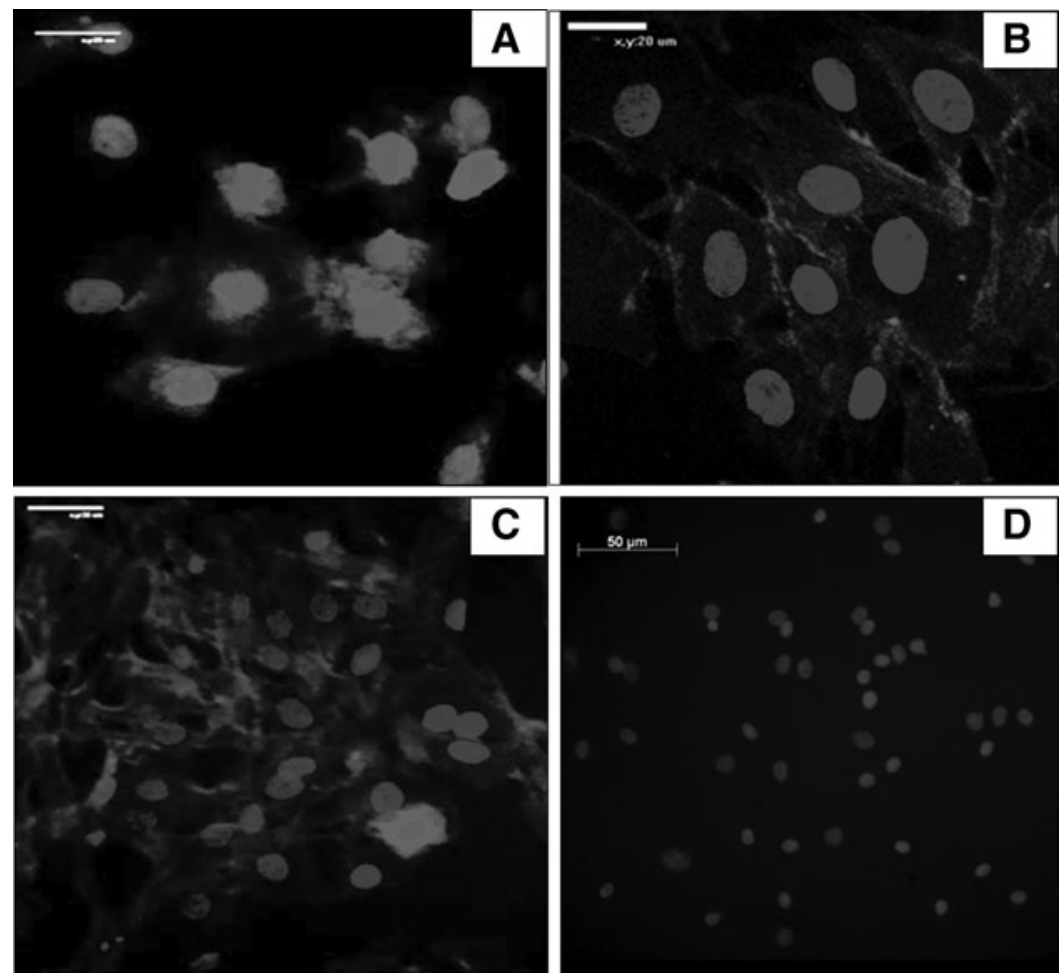

FIG. 5. Representative images of $\beta$-catenin immunofluorescent staining in endometrial stromal cells collected on days 2-4 of the estrous cycle. Images depict (A) the nuclear localization of $\beta$-catenin after $2 \mu \mathrm{M}$ BIO treatment and (B) the cytosolic localization of $\beta$-catenin after $10 \mu \mathrm{M}$ XAV939 treatment. (C) An image of the biological control sample is shown. (D) Primary antibody control. The cell nuclei were stained with DAPI and colocalized with $\beta$-catenin. Scale bars: $30 \mu \mathrm{m}$ (A), $20 \mu \mathrm{m}$ (B, C), $50 \mu \mathrm{m}$ (D). 
A
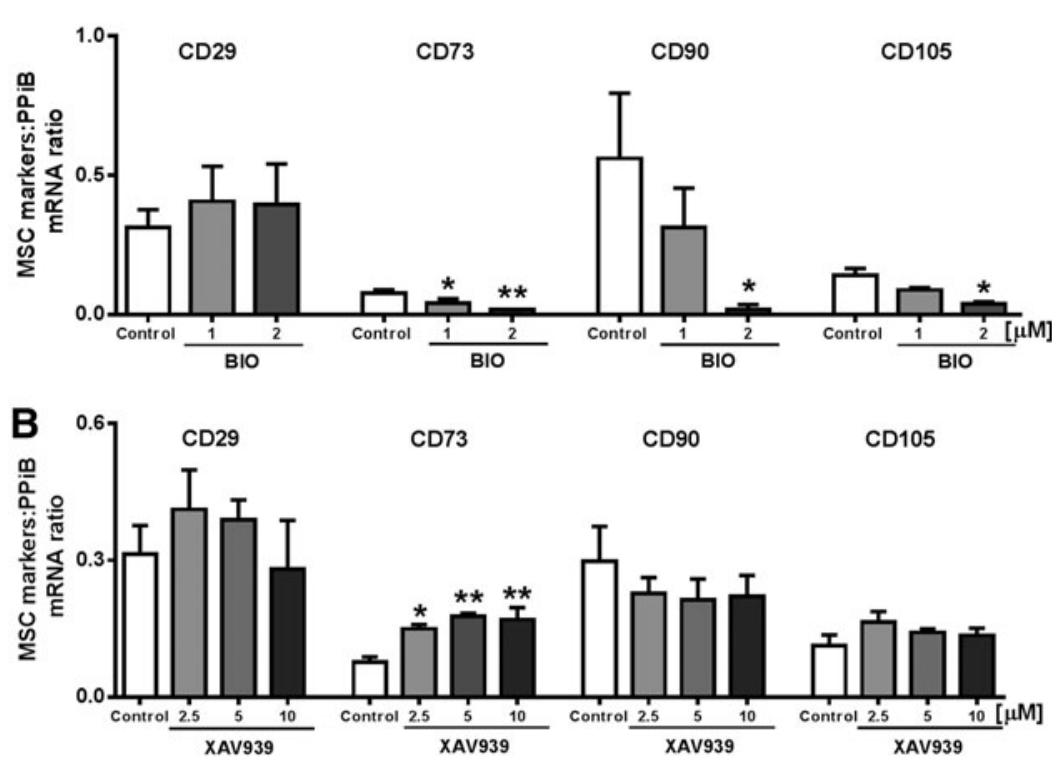

C

CD90

CD105

FIG. 6. Effect of XAV939 and BIO on MSC marker expression in endometrial stromal clones. Clones derived from endometrial stromal cells that were isolated on days 2-4 $(\mathbf{A}, \mathbf{B})$ and days 19-20 (C, D) of the estrous cycle. The results are shown as the mean+ SEM of four to five biological replicates. Each experiment consisted of a pool of clones collected from six replicate wells per treatment. The asterisks indicate significant differences compared with the control group $(* P<0.05$; $* * P<0.01$; *** $P<0.001)$.

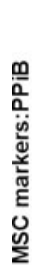
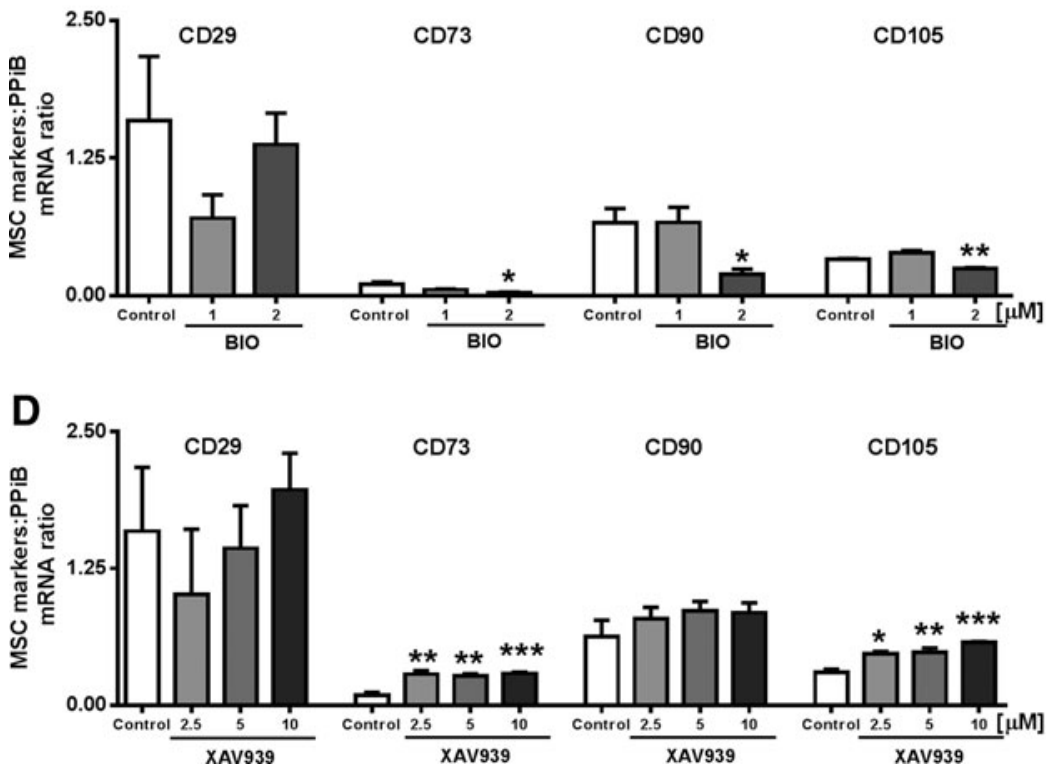

endometrial stromal clones regardless of the estrous cycle stage from which cells were collected.

\section{Effect of small molecules on multilineage differentiation potential of endometrial stromal cells}

To investigate the effect of the $\mathrm{Wnt} / \beta$-catenin pathway in the mesenchymal lineages differentiation, endometrial stromal cells were cultured in specific induction media supplemented with BIO (Fig. 7). Morphological features such as lipid droplets (Fig. 7A-C), typical for adipocytes, were observed in cells cultured with differentiation medium alone (Fig. 7A) and in cultures treated with $\mathrm{BIO}$ at a concentration of $1 \mu \mathrm{M}$ (Fig. 7B) and $2 \mu \mathrm{M}$ (Fig. 7C). Slight reduction of lipid vacuoles was observed in cultures treated with BIO $2 \mu \mathrm{M}$ (Fig. 7C) when compared to the cells treated with $\mathrm{BIO}$ at a concentration $1 \mu \mathrm{M}$ (Fig. 7B) and unstimulated cells that were cultured with adipogenic medium alone (Fig. 7A). In chondrogenic differentiation, stromal cells showed strong Alcian blue staining of proteoglycans in both medium without BIO (Fig. 7D) and in media supplemented with $\mathrm{BIO}$ (Fig. 7E, F for BIO 1 and $2 \mu \mathrm{M}$, respectively).

No staining was observed in nondifferentiation media (control media) without BIO (Supplementary Fig. S1D; Supplementary Data are available online at www.liebertpub.com/scd) and with BIO (Supplementary Fig. S1E, F). Calcium deposits indicating induction of the osteoblasts were observed in cells cultured in osteogenic medium without BIO (Fig. 7G) and with BIO (Fig. 7H, I). Control cultures failed to produce calcium 

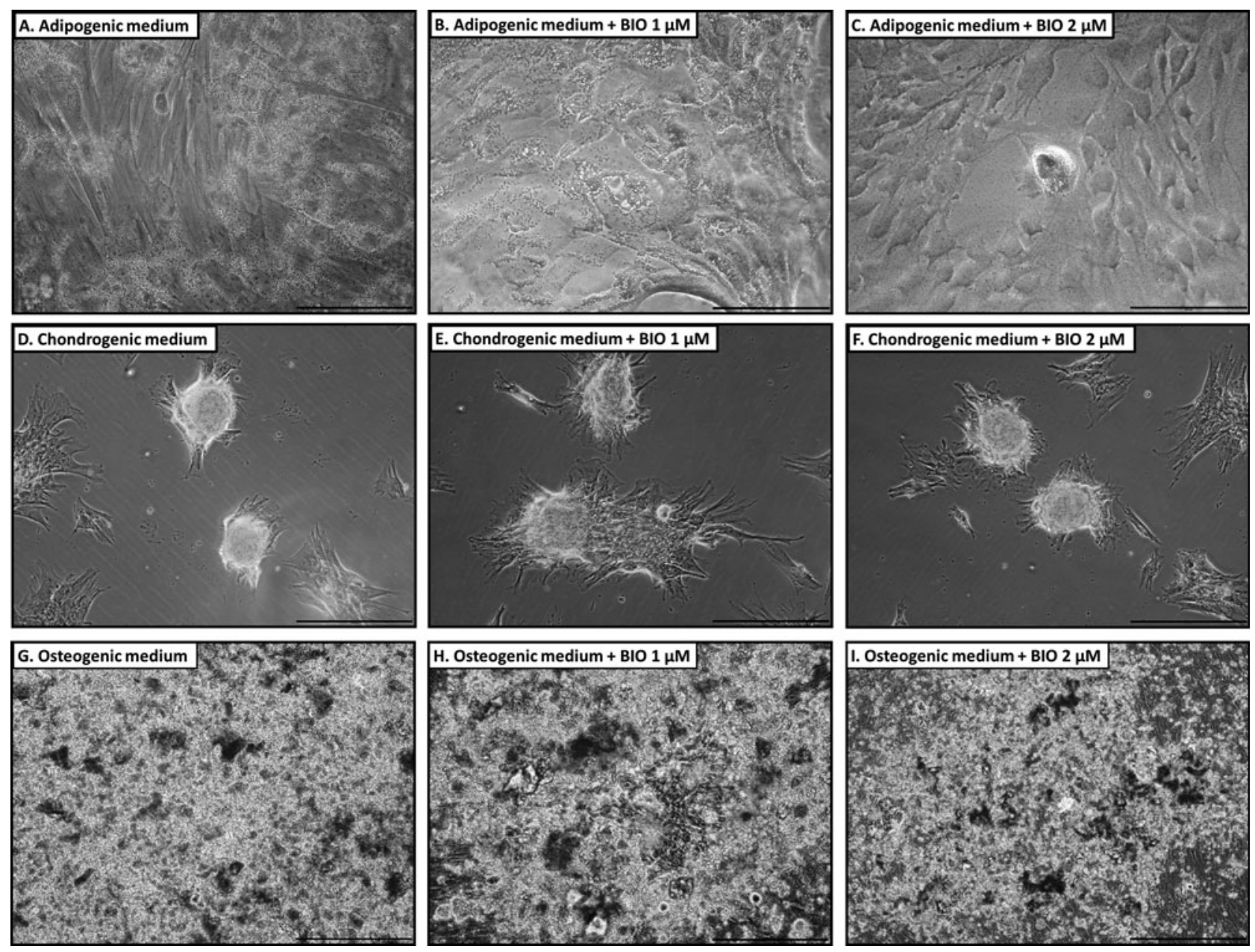

FIG. 7. Representative images depicting effect of BIO on multilineage differentiation of endometrial stromal cells. (A, B, C) Adipogenic differentiation indicated by Oil Red O staining of lipid droplets. (C) BIO $2 \mu \mathrm{M}$ inhibited adipogenic differentiation. (D), E, F). Proteoglycans visualized by Alcian blue indicated chondrogenic differentiation. (G, H, I) Osteogenic differentiation demonstrated by calcium deposits. No effect of BIO on chondrogenic and osteogenic induction was observed. Scale bars: $200 \mu \mathrm{m}$ (A-I).

deposits (Supplementary Fig. S1G, H). For chondrogenesis and osteogenesis no visible effect of BIO was observed.

No effect on the expression of lineage specific marker genes was observed during the $\mathrm{Wnt} / \beta$-catenin pathway activation (Fig. 8A-C). Although morphologically adipogenesis was reduced in cells cultured with adipogenic medium supplemented with BIO $2 \mu \mathrm{M}$, no changes in $L P L$ marker gene were observed (Fig. 8A).

The second strategy was to verify whether endometrial stromal clones undergo spontaneous multilineage differentiation when cultured in a nondifferentiating medium (DMEM/12 with $10 \%$ FBS) supplemented with the $\mathrm{Wnt} / \beta$-catenin pathway activator and inhibitor (Fig. 8D, E). Stromal clones underwent spontaneous adipogenic (Fig. 8D) and osteogenic transition (Fig. 8E), but not chondrogenic transition with BIO administration. BIO treatment decreased the level of adipocyte gene $L P L$ at both concentrations $(P<0.05$ for 1 and $2 \mu \mathrm{M}$ BIO) when compared to the control group (Fig. 8D). In contrast, $2 \mu \mathrm{M}$ BIO treatment increased the expression of osteocyte gene $B G L A P(P<0.05)$ (Fig. 8E). The presence of XAV 939 at a concentration of $10 \mu \mathrm{M}$ reduced levels of $L P L$ expression (Fig. 8D), whereas did not have effect on BGLAP levels (Fig.
$8 \mathrm{E})$. The expression of chondrocyte marker gene $A C A N$ was observed neither with BIO nor with XAV939 administration. Although histological analysis of stromal clones treated with both stimulators of $\mathrm{Wnt} / \beta$-catenin pathway, revealed no signs of adipogenic or osteogenic differentiation (Supplementary Fig. S2). The results obtained by real-time PCR analysis suggest that endometrial stromal clones have the potential to undergo spontaneous differentiation into osteoblasts during 14 days of culture (Fig. 8E). The effect of Wnt/ $\beta$-catenin pathway activation in stromal clones suggests that the Wnt pathway directs differentiation toward the osteogenic lineage at the expense of the adipogenic lineage.

\section{Discussion}

Stem/progenitor cells have been identified in a wide spectrum of adult tissues based on their unique functional properties [2-8]. Gargett et al. were the first to use clonogenicity assays to provide evidence that stem/progenitor cells exist in human endometrium [10]. In this study, we used a similar approach to demonstrate, for the first time that chemical modulators of $\mathrm{Wnt} / \beta$-catenin signaling influenced 

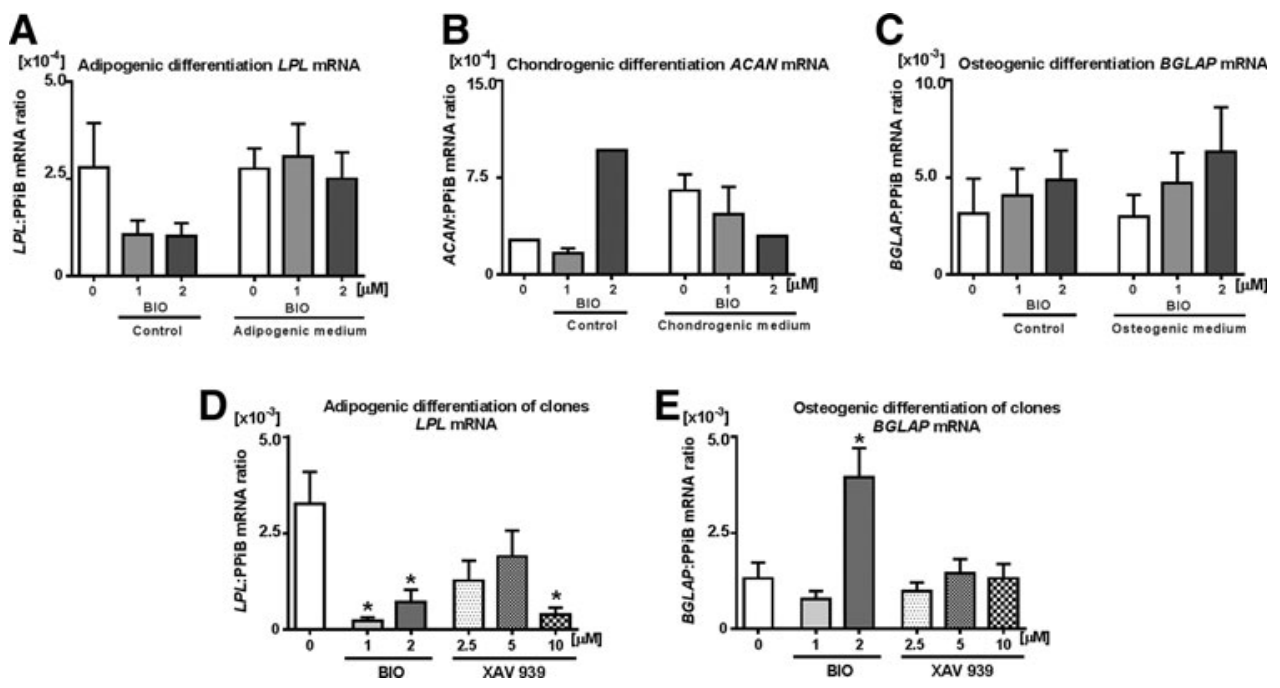

FIG. 8. Effect of BIO on lineage-specific marker gene expression in endometrial stromal cells. Subconfluent cells cultured in differentiation media show the expression of (A) adipocyte-specific gene $L P L,(\mathbf{B})$ chondrocyte-specific gene ACAN, (C) osteoblast-specific gene BGLAP. (D, E). Effect of BIO and XAV 939 on lineage-specific marker gene expression in spontaneously differentiated endometrial stromal clones. The pattern of expression of (D) adipocyte-specific gene $L P L,(\mathbf{E})$ osteoblastspecific gene BGLAP. The results are shown as the mean + SEM of three to four biological replicates. Each experiment consisted of a pool of cultures collected from five to six replicate wells per treatment. The asterisks indicate significant differences compared with the control group $(* P<0.05)$.

the clonogenicity and expression levels of MSC markers in porcine endometrial stem cells.

Our data revealed that porcine endometrial stromal clones possess higher levels of MSC marker expression than primary cultures, regardless of the estrous cycle stage at tissue collection, strongly suggesting that stem/progenitor cells are enriched in endometrial stromal clones. The clonogenicity assay not only allowed to separate stem cells from the entire pool of isolated and cultured cells, but it also enabled to identify clones that have the greatest potential to expand in the culture. This self-renewal ability is considered to be the fundamental phenomenon driving endometrial tissue regeneration [10]. The initial number of seeded cells affects the propagation of bone marrow MSC in human [34] and endometrial stromal cells in human [4] and pigs [8]. High-density plating contributes to the slow growth of cells due to the cell-to-cell contact or factors secreted into the culture medium [34].

Moreover, higher cloning density results in final lower clonogenicity because of overlapping individual clones that are counted as one when they are merged $[4,8]$. In the present study, we applied the clonal density of 300 cells/ $\mathrm{cm}^{2}$. We observed well-separated clones at passage 1 . Chan et al. found clonal density of 300 cells $/ \mathrm{cm}^{2}$ suitable for study of clonogenicity of primary endometrial stromal cells, and 500 cells $/ \mathrm{cm}^{2}$ for primary epithelial cells [2]. Contrary to our data, other studies [2,10] are performed on primary cells at passage 0 obtained by double selection using BerEP4 and CD45-coated magnetic beads that might cause divergence in the interpretation of the results. Thus, further investigations are needed to explain the difference between the number of passage and clonal potency.

Furthermore, our data are consistent with those obtained in humans, where high levels of the MSC surface markers CD29 and CD90 are expressed in clonally derived human endometrial stromal cells at passage 4 [4]. Moreover, it was previously shown that among the MSC markers not only
CD29 and CD90 are expressed in pig endometrial stromal cells, but also $C D 44, C D 73$, and $C D 105$, and the pluripotency markers NANOG, POU5F1, and SOX2 [8,9]. Realtime PCR data presented in this study and our previous work [8] demonstrate that the porcine endometrial stromal cells express CD73 and CD105 markers on mRNA level. Low mRNA level of both MSC markers might relate to differentiation of stromal cells toward development of uterine receptivity for implantation and for further maintenance of pregnancy in the uterus.

Flow cytometric analysis revealed that endometrial stromal cells are negative for CD73 and CD105, suggesting that both surface markers are either not expressed in porcine endometrial cells or commercially available antibodies against human tissues did not cross react with the porcine epitopes. These results are partially consistent with those obtained in ovine endometrial cells, where selective MSC markers (SUSD2, PDGFRB, CD146, CD73, CD90, and CD105) were not detectable [35].

The major finding of the present study is that the $\mathrm{Wnt} / \beta$ catenin pathway controls the clonogenicity of endometrial stromal cells in vitro. To investigate the mechanism of stromal clone development, we employed the small molecule inhibitor (XAV939) and activator (BIO), of the canonical Wnt pathway. The usefulness of these molecules to study proliferation, migration, and colony growth of human cancer cells, [30] and the differentiation potency of hESCs [24], has been demonstrated previously. We applied this method successfully to establish the importance of the Wnt pathway in regulating endometrial stromal cell self-renewal and differentiation. When culture media were supplemented with the Wnt activator, a reduction in the number of large clones and a concomitant escalation in small clones were observed.

Previous data suggest that large clones are originated from putative stem/progenitor cells, whereas small ones 
contain transit-amplifying cells that give rise to mature, terminally differentiated cells [6,36]. In accordance with these data, our study revealed that activation of the canonical Wnt pathway promoted differentiation of endometrial stromal stem/progenitor cells. It has been previously demonstrated that BIO, which acts as a highly potent inhibitor of GSK-3, directs hESCs to become definitive endoderm with hepatic potential [37]. Similarly, Davidson et al. demonstrated that activation of $\mathrm{Wnt} / \beta$-catenin signaling in hESCs spurs them to adopt the morphological characteristics of differentiated cells and promotes the expression of stem cell surface markers, including GCTM2 and CD9, and pluripotency markers [24].

In this study, stromal clones cultured with XAV939 had upregulated expression of selected MSC marker genes (CD73, CD105), whereas those cultured with BIO had downregulated expression of all studied MSC marker genes observed. Data concerning BIO application support the observed effects using clonogenic assays, suggesting that canonical Wnt pathway activation leads to MSC differentiation. Lack of stimulatory effect of XAV 939 on clonogenicity might suggest low specificity of this small molecule to endometrial stromal cells or demonstrate other effects as it was shown for human breast cancer cells [30], hESCs [38], and neuroblastoma cell lines [39].

These findings are consistent with an earlier report demonstrating that Wnt pathway activation in hESCs promotes loss of self-renewal and directs cells toward differentiation [24]. Moreover, activation of Wnt signaling early in adipogenesis blocks the differentiation of preadipocytes, whereas disruption of extracellular Wnt signaling results in spontaneous adipogenesis [40]. Similarly, in hair follicles (HFs), when canonical Wnt signaling is inactive, Tcf3 cells maintain bulge stem cells in an undifferentiated state. However, when the pathway becomes active, stem cells exit the niche, activate Wnt target genes, proliferate, and differentiate along the HF lineage [41].

In this study, we showed for the first time that levels of the MSC marker genes CD73, CD90, and CD105 were altered following Wnt pathway modulation, suggesting that these MSC marker genes are potential Wnt targets.

The present study demonstrated that the activation of the canonical Wnt signaling moderately influences differentiation potency into mesenchymal lineages when cells were cultured in specific media. Marker gene expression shown only tendency to grow in osteogenic-induced cells treated with $\mathrm{BIO}$, whereas the level of $A C A N$ decreased when the $\mathrm{Wnt} / \beta$-catenin pathway activator was added into chondrogenic medium. Moreover, we investigated whether clonogenic stromal cells undergo spontaneous multilineage differentiation. Demonstrated in our study, existence of an inverse correlation between spontaneous adipogenesis and osteogenesis promoted by BIO is generally in agreement with the experimental evidence from porcine adipose-derived MSCs [42], rat [43], and mouse marrow stromal cells [44].

Activation of the canonical Wnt signaling through ectopic expression of Wnt3a [45] and Wnt1 [46] leads to the inhibition of peroxisome proliferator activator receptor (PPAR $\gamma)$ resulting in the prevention of 3T3-L1 cells adipogenic differentiation. Conversely, a constitutive overexpression of DKK1, which is the Wnt/ $\beta$-catenin inhibitor, promoted adipogenesis [47], whereas a DKK1 knockdown by siRNA inhibited this process in human [48]. Many reports suggested that in contrast to adipogenesis, activation of the canonical Wnt pathway results in the stimulation of osteogenesis $[42,43,44]$. Whereas administration of lithium chloride inhibited GSK-3 and led to osteogenesis in MC3T3 cells [46], Wnt10b promotes osteogenesis in vivo [49]. A large body of evidence suggested significant role of $\mathrm{Wnt} / \beta$-catenin pathway in adipogenesis and osteogenesis [42-50].

Data obtained for human MSC indicated that inhibitors of Wnt pathway promote early chondrogenesis [51]. Similar response to Wnt pathway activator was observed in bone marrow MSC in mice [52]. In our study, inhibition of Wnt/ $\beta$-catenin pathway resulted in the downregulation of adipogenic marker gene $L P L$, whereas has no effect on BGLAP, osteogenic marker expression. The histological analysis showed no signs of spontaneous multilineage differentiation of stromal clones administrated with the small molecules. Considering the very low levels of marker genes, we can assume that histological method used in our study was not sensitive enough to detect changes in cellular morphology associated with differentiation process in clones.

However, histological analysis of endometrial stromal subconfluent cells cultured in differentiation media, indicated lineage-specific morphological features, suggesting that culture conditions might significantly affect differentiation capacity of cells. In our study, spontaneous differentiation of stromal clones was detected on molecular level, whereas media-induced differentiation of subconfluent cells was observed on morphological base. Although these two experimental conditions are different, they indicate that stromal cells have the potency to differentiate. Our previous study demonstrated that endometrial stromal cells possess the ability to differentiate into mesenchymal lineages when cultured in lineage-specific induction media [8]. Similar results observed on clonally derived stromal cells in human [10] confirmed their multilineage differentiation capacity.

In conclusion, to our knowledge, this is the first study to document the importance of the $\mathrm{Wnt} / \beta$-catenin pathway in regulating the maintenance and functionality of porcine endometrial stromal stem/progenitor cells. Endometrial renewal occurs cyclically, and this process is essential in preparing the uterus for embryo implantation. In the pig, a nonmenstruating species, the endometrium undergoes phases of growth, establishment of uterine receptivity and apoptosis, whereas the shedding of mucosal lining of the uterus does not occur [53]. At the end of the estrous cycle, endometrial cells undergo apoptosis and necrosis. At the same time, new generation of cells proliferate and replenish the endometrial tissue to prepare the uterus to receive an embryo.

Contrary to the human and mouse, there is little information concerning the regeneration process in the pig. Our data suggest that cyclical switching from inhibition to activation of the $\mathrm{Wnt} / \beta$-catenin pathway governs the cyclical regeneration process in porcine endometrium. Further studies investigating the role of specific Wnt ligands and other exogenous stimulators are likely to provide additional mechanisms involved in regulating stem cell self-renewal and differentiation during the estrous cycle in the pig.

\section{Acknowledgments}

The authors kindly thank Chu Dinh Toi (Institute of Animal Reproduction and Food Research, Polish Academy 
of Science, Olsztyn) for generously providing adipogenic media and Dr. Beenu Moza Jalali (Institute of Animal Reproduction and Food Research of Polish Academy of Science, Olsztyn) for assistance in writing this article. This study was supported by the National Science Centre Poland (Grant PRELUDIUM No. 2012/05/N/NZ9/02388) and supported by the Polish Ministry of Science and Higher Education Research Grant No. 769/N-COST/2010/0, and funds appropriated to the Institute of Animal Reproduction and Food Research, Polish Academy of Sciences. The research is part of the doctoral thesis tasks of J.B. J.B. was supported by the European Union within the European Social Fund (RIM WiM).

\section{Author Disclosure Statement}

No competing financial interests exist.

\section{References}

1. Rando TA. (2006). Stem cells, ageing and the quest for immortality. Nature 441:1080-1086.

2. Chan RW, KE Schwab and CE Gargett. (2004). Clonogenicity of human endometrial epithelial and stromal cells. Biol Reprod 70:1738-1750.

3. Kato K, M Yoshimoto, K Kato, S Adachi, A Yamayoshi, T Arima, K Asanoma, S Kyo, T Nakahata, et al. (2007). Characterization of side-population cells in human normal endometrium. Hum Reprod 22:1214-1223.

4. Dimitrov R, T Timeva, D Kyurkchiev, M Stamenova, A Shterev, P Kostova, V Zlatkov, I Kehayov and S Kyurkchiev. (2008). Characterization of clonogenic stromal cells isolated from human endometrium. Reproduction 135:551558.

5. Cervello I, JA Martínez-Conejero, JA Horcajadas, A Pellicer and C Simon. (2007). Identification, characterization and co-localization of label-retaining cell population in mouse endometrium with typical undifferentiated markers Hum Reprod 22:45-51.

6. Chan RW and CE Gargett. (2006). Identification of labelretaining cells in mouse endometrium. Stem Cells 24:15291538.

7. Lupicka M, G Bodek, N Shpigel, E Elnekave and AJ Korzekwa. (2015). Identification of pluripotent cells in bovine uterus: in situ and in vitro studies. Reproduction 149:317-327.

8. Bodek G, J Bukowska, J Wisniewska and AJ Ziecik. (2015). Evidence for the presence of stem/progenitor cells in porcine endometrium. Mol Reprod Dev 82:182-190.

9. Miernik K and J Karasinski. (2012). Porcine uterus contains a population of mesenchymal stem cells. Reproduction 143:203-209.

10. Gargett CE, KE Schwab, RM Zillwood, HP Nguyen and D Wu. (2009). Isolation and culture of epithelial progenitors and mesenchymal stem cells from human endometrium. Biol Reprod 80:1136-1145.

11. Ferenczy A, G Bertrand and MM Gelfand. (1979). Proliferation kinetics of human endometrium during the normal menstrual cycle. Am J Obstet Gynecol 133:859867.

12. Wang Y, P Hanifi-Moghaddam, EE Hanekamp, HJ Kloosterboer, P Franken, J Veldscholte, HC van Doorn, PC Ewing, JJ Kim, et al. (2009). Progesterone inhibition of $\mathrm{Wnt} /$ beta-catenin signaling in normal endometrium and endometrial cancer. Clin Cancer Res 15:5784-5793.
13. Hayashi K, DW Erikson, SA Tilford, BM Bany, JA Maclean, EB Rucker, GA Johnson and TE Spencer. (2009). Wnt genes in the mouse uterus: potential regulation of implantation. Biol Reprod 80:989-1000.

14. Sato H, K Amagai, R Shimizukawa and Y Tamai. (2009). Stable generation of serum- and feeder free embryonic stem cell-derived mice with full germline-competency by using a GSK3 specific inhibitor. Genesis 47:414-422.

15. Reya T, AW Duncan, L Ailles, J Domen, DC Scherer, K Willert, L Hintz, R Nusse, and IL Weissman. (2003). A role for Wnt signalling in self-renewal of haematopoietic stem cells. Nature 423:409-414.

16. Gregorieff A, D Pinto, H Begthel, O Destree, M Kielman and H Clevers. (2005). Expression pattern of Wnt signaling components in the adult intestine. Gastroenterology 129: 626-638.

17. Bastide P, C Darido, J Pannequin, R Kist, S Robine, C Marty-Double, F Bibeau, G Scherer, D Joubert, et al. (2007). Sox9 regulates cell proliferation and is required for Paneth cell differentiation in the intestinal epithelium. J Cell Biol 178:635-648.

18. Etheridge SL, GJ Spencer, DJ Heath and PG Genever. (2004). Expression profiling and functional analysis of wnt signaling mechanisms in mesenchymal stem cells. Stem Cells 22:849-860.

19. Boland GM, G Perkins, DJ Hall and RS Tuan. (2004). Wnt 3a promotes proliferation and suppresses osteogenic differentiation of adult human mesenchymal stem cells. J Cell Biochem 93:1210-1230.

20. Bilir B, O Kucuk and CS Moreno. (2013). Wnt signaling blockage inhibits cell proliferation and migration, and induces apoptosis in triple-negative breast cancer cells. J Transl Med 11:280.

21. Huang SM, YM Mishina, S Liu, A Cheung, F Stegmeier, GA Michaud, O Charlat, E Wiellette, Y Zhang, et al. (2009). Tankyrase inhibition stabilizes axin and antagonizes Wnt signalling. Nature 461:614-620.

22. Hedgepeth CM, LJ Conrad, J Zhang, HC Huang, VM Lee and PS Klein. (1997). Activation of the Wnt signaling pathway: a molecular mechanism for lithium action. Dev Biol 185:82-91.

23. Trowbridge JJ, A Xenocostas, RT Moon and M Bhatia. (2006). Glycogen synthase kinase 3 is an in vivo regulator of hematopoietic stem cell repopulation. Nat Med 12: 89-98.

24. Davidson KC, AM Adams, JM Goodson, CE McDonald, JC Potter, JD Berndt, TL Biechele, RJ Taylor and RT Moon. (2012). Wnt/ $\beta$-catenin signaling promotes differentiation, not self-renewal, of human embryonic stem cells and is repressed by Oct4. Proc Natl Acad Sci 109:44854490.

25. Nguyen HP, CN Sprung and CE Gargett. (2012). Differential expression of Wnt signaling molecules between preand postmenopausal endometrial epithelial cells suggests a population of putative epithelial stem/progenitor cells reside in the basalis layer. Endocrinology 153:2870-2883.

26. Kiewisz J, MM Kaczmarek, A Andronowska, A Blitek, and AJ Ziecik. (2011). Gene expression of WNTs, $\beta$-catenin and E-cadherin during the periimplantation period of pregnancy in pigs-involvement of steroid hormones. Theriogenology 76:687-699.

27. Sukjumlong S, AM Dalin, L Sahlin and E Persson. (2005). Immunohistochemical studies on the progesterone receptor (PR) in the sow uterus during the oestrous cycle and in 
inseminated sows at oestrus and early pregnancy. Reproduction 129:349-359.

28. Dalin AM, T Nanda, F Hulten and S Einarsson. (1995). Ovarian activity at naturally attained oestrus in the sow. An ultrasonographic and LH study. Acta Vet Scand 36:377-382.

29. Gawronska-Kozak B, JA Manuel and V Prpic. (2007). Ear mesenchymal stem cells (EMSC) can differentiate into spontaneously contracting muscle cells. J Cell Biochem 102:122-135.

30. Bao R, T Christova, S Song, S Angers, X Yan and L Attisano. (2012). Inhibition of tankyrases induces axin stabilization and blocks Wnt signalling in breast cancer cells. PLoS One 7:e48670.

31. Gawronska-Kozak B. (2014). Preparation and differentiation of mesenchymal stem cells from ears of adult mice. Methods Enzymol 538:1-13.

32. Bolzan E, A Andronowska, G Bodek, E MorawskaPucinska, K Krawczynski, A Dabrowski and AJ Ziecik. (2013). The novel effect of hCG administration on luteal function maintenance during the estrous cycle/pregnancy and early embryo development in the pig. Pol J Vet Sci 16:323-332.

33. Zhao $\mathrm{H}$ and FD Fernald. (2005). Comprehensive algorithm for quantitative real time polymerase chain reaction. J Comput Biol 12:1045-1062.

34. Colter DC, I Sekiya and DJ Prockop. (2001). Identification of a subpopulation of rapidly self-renewing and multipotential adult stem cells in colonies of human marrow stromal cells. Proc Natl Acad Sci U S A 98:7841-7845.

35. Letouzey V, KS Tan, JA Deane, D Ulrich, S Gurung, YR Ong and CE Gargett. (2015). Isolation and characterisation of mesenchymal stem/stromal cells in the ovine endometrium. PLoS One 10:e127531.

36. Xu J, FF Hu, YG Cui, J Luo, CY Jiang, L Gao, XQ Qian, YD Mao and JY Liu. (2011). Effect of estradiol on proliferation and differentiation of side population stem/progenitor cells from murine endometrium. Reprod Biol Endocrinol 9:103.

37. Bone HK, AS Nelson, CE Goldring, D Tosh and MJ Welham. (2011). A novel chemically directed route for the generation of definitive endoderm from human embryonic stem cells based on inhibition of GSK-3. J Cell Sci 124:1992-2000.

38. Palpant NJ, L Pabon, JS Rabinowitz, BK Hadland, CL Stoick-Cooper, SL Paige, ID Bernstein, RT Moon and CE Murry. (2013). Transmembrane protein 88: a Wnt regulatory protein that specifies cardiomyocyte development. Development 140:3799-3808.

39. Tian XH, WJ Hou, Y Fang, J Fan, H Tong, SL Bai, Q Chen, H $\mathrm{Xu}$ and Y Li. (2013). XAV939, a tankyrase 1 inhibitior, promotes cell apoptosis in neuroblastoma cell lines by inhibiting Wnt/ $\beta$-catenin signaling pathway. J Exp Clin Cancer Res 32:100.

40. Bennett CN, SE Ross, KA Longo, L Bajnok, N Hemati, KW Johnson, SD Harrison and OA MacDougald. (2002). Regulation of Wnt signaling during adipogenesis. J Biol Chem 277:30998-31004.

41. Haegebarth A and H Clevers. (2009). Wnt signaling, lgr5, and stem cells in the intestine and skin. Am J Pathol 174:715-721.

42. Li HX, X Luo, RX Liu, YJ Yang and GS Yang. (2008). Roles of Wnt/beta-catenin signaling in adipogenic differentiation potential of adipose-derived mesenchymal stem cells. Mol Cell Endocrinol 291:116-124.
43. Beresford JN, JH Bennett, C Devlin, PS Leboy and ME Owen. (1992). Evidence for an inverse relationship between the differentiation of adipocytic and osteogenic cells in rat marrow stromal cell cultures. J Cell Sci 102(Pt 2):341-351.

44. Dorheim MA, M Sullivan, V Dandapani, X Wu, J Hudson, PR Segarini, DM Rosen, AL Aulthouse and JM Gimble. (1993). Osteoblastic gene expression during adipogenesis in hematopoietic supporting murine bone marrow stromal cells. J Cell Physiol 154:317-328.

45. Kawai M, S Mushiake, K Bessho, M Murakami, N Namba, C Kokubu, T Michigami, and K Ozono. (2007). Wnt/Lrp/ beta-catenin signaling suppresses adipogenesis by inhibiting mutual activation of PPARgamma and C/EBPalpha. Biochem Biophys Res Commun 363:276-282.

46. Moldes M, Y Zuo, RF Morrison, D Silva, BH Park, J Liu, and SR Farmer. (2003). Peroxisome-proliferator-activated receptor gamma suppresses Wnt/beta-catenin signalling during adipogenesis. Biochem J 376(Pt 3):607-613.

47. Christodoulides C, M Laudes, WP Cawthorn, S Schinner, M Soos, S O'Rahilly, JK Sethi and A Vidal-Puig. (2006). The Wnt antagonist Dickkopf-1 and its receptors are coordinately regulated during early human adipogenesis. J Cell Sci 119(Pt 12):2613-2620.

48. Park JR, JW Jung, YS Lee and KS Kang. (2008). The roles of Wnt antagonists Dkk1 and sFRP4 during adipogenesis of human adipose tissue-derived mesenchymal stem cells. Cell Prolif 41:859-874.

49. Bennett CN, H Ouyang, YL Ma, Q Zeng, I Gerin, KM Sousa, TF Lane, V Krishnan, KD Hankenson, et al. (2007). Wnt10b increases postnatal bone formation by enhancing osteoblast differentiation. J Bone Miner Res 22:1924-1932.

50. Galli C, M Piemontese, S Lumetti, E Manfredi, GM Macaluso and G Passeri. (2013). GSK3b-inhibitor lithium chloride enhances activation of Wnt canonical signaling and osteoblast differentiation on hydrophilic titanium surfaces. Clin Oral Implants Res 24:921-927.

51. Im GI and Z Quan. (2010). The effects of Wnt inhibitors on the chondrogenesis of human mesenchymal stem cells. Tissue Eng Part A 16:2405-2413.

52. Baghaban Eslaminejad M and N Fallah. (2014). Small molecule-BIO accelerates and enhances marrow-derived mesenchymal stem cell in vitro chondrogenesis. Iran J Med Sci 39:107-116.

53. Gargett CE. (2007). Uterine stem cells: what is the evidence? Hum Reprod Update 13:87-101.

Address correspondence to: Dr. Gabriel Bodek

In Vitro and Cell Biotechnology Laboratory Institute of Animal Reproduction and Food Research Polish Academy of Sciences

Tuwima 10

Olsztyn 10-748

Poland

E-mail: g.bodek@pan.olsztyn.pl

Received for publication February 26, 2015

Accepted after revision September 22, 2015

Prepublished on Liebert Instant Online September 28, 2015 